International Journal of the Physical Sciences Vol. 6(28), pp. 6394-6409, 9 November, 2011

Available online at http://www.academicjournals.org/lJPS

DOI: $10.5897 /$ IJPS11.199

ISSN 1992 - 1950 C2011 Academic Journals

Full Length Research Paper

\title{
Optimal power flow solution using adaptive tabu search
}

\section{Thanatchai Kulworawanichpong}

\author{
School of Electrical Engineering, Suranaree University of Technology, Nakhon Ratchasima 30000, Thailand. \\ E-mail: thanatchai@gmail.com. \\ Accepted 3 August, 2011
}

\begin{abstract}
This paper illustrates an application of adaptive tabu search (ATS) to optimal power flow (OPF) problems in comparison with some effective mathematical and evolutionary optimization methods. Although, the ATS was originally developed for solving a combinatorial optimization problem whose parameters are discrete, it has the ability to handle continuous variables by treating them as discrete ones with a very small variable step-size to gain accuracy. The proposed algorithm was tested with 9bus and 300-bus test systems to represent a small-scale and a comparatively large-scale power system, respectively. Each test power system was challenged by performing three test cases. The first test case was given by applying a quadratic function to generators' fuel-cost curve, whereas a non-smooth fuelcost function was assigned to the second. In addition, the system voltage profile was considered and set as the objective function to be minimized in the last test case. The comparisons among solutions obtained by sequential quadratic programming (SQP), evolutionary programming (EP) and the ATS were carried out, from which satisfactory results and the selection of solution methods to OPF problems were summarized.
\end{abstract}

Key words: Optimal power flow problem, sequential quadratic programming, evolutionary programming, adaptive tabu search, quadratic fuel cost, non-smooth fuel cost.

\section{INTRODUCTION}

To date, an electrical power system is very large and obviously complicated due to technological enhancement of power system engineering. Increase of electrical energy consumption often leads to extending and upgrading an existing power transmission and distribution network to serve all customers sufficiently, effectively and economically. To achieve good performance for power delivery, a real power dispatching problem must be taken into account in order to minimize total generation cost (ElAbiad and Jaimes, 1969). Also, appropriate reactive power flows relate to power losses and system voltage profiles, directly. In this viewpoint, tap setting of underload tap-changing transformers (ULTCs), voltage magnitude of voltage-controlled buses or installing re-active power sources can improve voltage characteristics and reduce power losses considerably (Mansour and Abdel, 1984). Dommel and Tinney (1968) proposed the method of optimal power flow (OPF), which employs allocation of real power generated by generators to co-operate with controlling ULTCs, magnitude of voltage-controlled buses or reactive power sources for minimizing the system objective.

As a general approach, a typical OPF problem employs an optimization method for balancing the power flow equations and finding the optimum solution. The solution satisfies the constraint of the minimum value of an objective function, that is, total generation cost for most cases, within the entire search space. The OPF problem is in general non-convex and non-linear. It may exist in many local minima. Many mathematical techniques have been developed and applied to this problem such as linear programming, interior point method, etc., (Wood and Wollenburg, 1996). The algorithms essentially need some problem simplification such that the problem is linear or convex. Thus, a true global minimum cannot be guaranteed. Then, stochastic optimization methods such as genetic algorithms (GAs), simulated annealing (SA), artificial neural network (ANN) and evolutionary 
programming (EP) (Walters and Sheble 1993; Pradhan and Lee, 2009; Yang et al., 1996; Wong, 1997; Herault, 2000) were applied for solving such a problem directly without any simplification. The followings are some recent reviewed literature concerning with optimal power flow solutions.

Santos and Costa (1995) presented a novel approach for solving optimal power flow problems based on Newton's method. Using the Lagrangian functions to combine problem constraints, the nonlinear optimization problem can be solved effectively. Muriithi (1996) presented the problem of power flow optimization taking into account the principles of economics and reliability as its objective. This paper used some efficient mathematical programs, such as the steepest descent method, the quadratic programming and the gradient projection method. Leung at al. (2000) proposed a genetic algorithm (GA) for solving optimal power flow problems in power systems which are equipped with flexible AC transmission systems (FACTS). Abido et al. (2002a) proposed the optimal power flow solution by using tabu search method (TS). The test was simulated by using the IEEE 30-bus test system with four test cases. The result of this simulation concluded that tabu search method is capable to solve optimal power flow problem with the lowest objective function and the fastest convergence. Abido (2002b) proposed a power flow optimization by means of particle swarm optimization (PSO). This work was carried out by simulating the IEEE 30-bus test system with the fuel-cost function is the system objective. Gaing (2005) employed the mixedinteger particle swarm optimization (MIPSO) for solving optimal power flow problems with a combination of continuous and discrete control variables. The total production cost with smooth and non-smooth curves was used as the system objective to be minimized. The IEEE 9-bus and 26-bus test power systems were challenged. Vaisakb and Srinivas (2005) proposed optimal power flow solutions by using differential evolution (DE), which was tested in the IEEE 30-bus test system with fuel-cost objective functions. Younes et al. (2007) proposed the optimal power flow solutions using genetic algorithms. The IEEE 57-bus test system was used together with the total production cost as the objective function. The simulations were conducted by using MATHPOWER software package. Tangpatiphan and Yokoyama (2008) presented evolutionary programming with artificial neural network by solving the transient stability based optimal power flow problems. The swing equation and the rotor angle dynamic were determined. The IEEE 30-bus test system was used for the test. Wenjuan et al. (2008) presented the problem of reactive power planning (RPP) to determine the optimal location and the size of the reactive power sources. This work included the consideration of (1) the ability of power transfer capability,
(2) fuel-cost minimization and (3) the voltage stability enhancement. Oumarou et al. (2009) presented the optimal power flow solution by using the particle swarm optimization. The IEEE 30-bus test power system was used for the test to adjust generators' powers, bus voltage magnitudes, reactive powers from the var sources and transformer taps. Tangpatipphan et al. (2009) presented the evolutionary programming for solving the optimal power flow problem with consideration of steady-state voltage stability. The system objective function was the total production cost with system security and voltage stability constraints. In this paper, the IEEE 30-bus test system was employed. Va et al. (2010) presented the optimal power flow solution using some efficient intelligent search methods. Genetic algorithms, differential evolution and ant colony optimization (ACO) were challenged with the IEEE 30bus test system.

These methods can successfully manipulate a problem in non-convex or non-linear. Therefore, an obtained optimal solution is more accurate and realistic. Unfortunately, these algorithms normally take lengthy calculation time when compared with the mathematical optimization methods. Since the beginning of the previous decade, tabu Search (TS) and its variants, such as adaptive tabu search (ATS) have been introduced and performed drastically improved search performance. Regarded as one of the random search processes, ATS provides a near global minimum by successfully avoiding localminimum traps. Successful applications of the ATS have emerged (Mantawy et al., 1998; Mori and Hayashi, 1998; Mori and Ogita, 1999a; Mori and Sone, 1999b; Denna et al., 1999; Kulworawanichpong and Sujitjorn, 2002; Abido, 2002a; Lin et al., 2002). Although, ATS algorithm was developed as a stochastic optimization technique, it can find an optimal solution within a short calculation time. Consequently, this paper applied ATS for solving the OPF problem.

\section{PROBLEM FORMULATION}

The OPF problem is a problem that considers dispatching real power among power generation plants sufficiently, effectively and economically together with reactive power-flow control to gain the minimum for some particular objective, normally the total generation cost. The OPF is in nature non-convex and non-linear; there exist many local minima that can trap an inefficient optimization method. Due to largely sizing and complexity of the OPF formulation in the past where a high-speed computer was rare, it could be decomposed into two consecutive sub-problems, such as P- and Qproblems (Shoults and Sun, 1982). However, with continuously emerging high-speed computer technologies within the last two decades ago, a digital computer nowadays is able to handle bulky and very complicated problems. To combine the P- and Q-problems together, a set of control variables must be re-formed by combining all control variables altogether from both sub-problems. The 
combined OPF formulation is defined by the following explanation.

The main objective focuses on minimizing the total generation cost by considering real power output of all controlled generators, tap position of ULTCs, voltage magnitudes of the slack bus and voltage-controlled buses or reactive powers injected by reactive power sources as control variables (Wood and Wollenburg, 1996). Assuming that a given power system has the following properties, containing $\mathrm{N}_{\mathrm{PV}}$ voltage-controlled buses and $\mathrm{N}_{\mathrm{T}}$ ULTCs.

Let $\tilde{\mathrm{u}}$ be a control variable and be defined by:

$\tilde{\mathrm{u}}=\left[\begin{array}{c}\mathrm{P}_{\mathrm{Gi}} \\ \mathrm{V}_{\mathrm{j}} \\ \mathrm{V}_{\text {ref }} \\ \mathrm{T}_{\mathrm{p}}\end{array}\right]$

Where

$\mathrm{P}_{\mathrm{Gi}} \sim\left[\mathrm{P}_{\mathrm{Gi}}^{\min }, \mathrm{P}_{\mathrm{Gi}}^{\max }\right] ; \mathrm{i}=1,2, \ldots, \mathrm{N}_{\mathrm{G}}-1$

$\mathrm{V}_{\mathrm{j}} \sim\left[\mathrm{V}_{\mathrm{j}}^{\min }, \mathrm{V}_{\mathrm{j}}^{\max }\right] ; \mathrm{j}=1,2, \ldots, \mathrm{N}_{P V}$

$\mathrm{T}_{\mathrm{p}} \sim\left[\mathrm{T}_{\mathrm{p}}^{\min }, \mathrm{T}_{\mathrm{p}}^{\max }\right] ; \mathrm{p}=1,2, \ldots, \mathrm{N}_{\mathrm{T}}$

$\mathrm{V}_{\text {ref }} \sim\left[\mathrm{V}_{\mathrm{ref}}^{\min }, \mathrm{V}_{\mathrm{ref}}^{\mathrm{max}}\right]$

The formulation of the OPF problem is given as:

Minimize $F_{T}=\sum_{i=1}^{N_{G}} f\left(P_{G i}\right)$

Subjects to

1. Equality constraints: power mismatch equations:

$$
\begin{gathered}
\mathrm{P}_{\mathrm{sch}, \mathrm{k}}-\sum_{\mathrm{i}=1}^{\mathrm{N}_{\mathrm{B}}}\left|\mathrm{Y}_{\mathrm{ik}} \mathrm{V}_{\mathrm{i}} \mathrm{V}_{\mathrm{k}}\right| \cos \left(\theta_{\mathrm{ik}}+\delta_{\mathrm{k}}-\delta_{\mathrm{i}}\right)=0 \\
Q_{s c h, k}+\sum_{i=1}^{N_{B}}\left|Y_{i k} V_{i} V_{k}\right| \sin \left(\theta_{i k}+\delta_{k}-\delta_{i}\right)=0
\end{gathered}
$$

2. Inequality constraints: limits of control or state variables

$$
\begin{aligned}
& \mathrm{P}_{\mathrm{Gi}}^{\min } \leq \mathrm{P}_{\mathrm{Gi}} \leq \mathrm{P}_{\mathrm{Gi}}^{\max } \\
& \mathrm{Q}_{\mathrm{Gi}}^{\min } \leq \mathrm{Q}_{\mathrm{Gi}} \leq \mathrm{Q}_{\mathrm{Gi}}^{\max } \\
& \mathrm{V}_{\mathrm{j}}^{\min } \leq \mathrm{V}_{\mathrm{j}} \leq \mathrm{V}_{\mathrm{j}}^{\max } \\
& \mathrm{T}_{\mathrm{p}}^{\min } \leq \mathrm{T}_{\mathrm{p}} \leq \mathrm{T}_{\mathrm{p}}^{\max } \\
& \mathrm{V}_{\text {ref }}^{\min } \leq \mathrm{V}_{\text {ref }} \leq \mathrm{V}_{\text {ref }}^{\max }
\end{aligned}
$$

Voltage variations for all load buses to find optimal solutions for the OPF problem, an appropriate optimization method has to be chosen to handle its non-linear and non-convex nature. In fact, although there is no restriction for making selection, searching speed and accuracy are mainly the matter of concern. This paper attempts to demonstrate the effectiveness of three different optimization techniques, namely SQP, EP and ATS. Here, only sequential quadratic programming (SQPO and EP are discussed.

The general form of a non-linear optimization problem (Nash and Sofer, 1996) can initially be expressed as follows:

Minimize $f(x)$

Subjects to $g_{i}(x)=0 \quad ;$ for $i=1,2, \ldots, M_{E}$

$h_{j}(x) \leq 0 ;$ for $i=M_{E}+1, \ldots, M$

$\mathrm{I} \leq \mathrm{x} \leq \mathrm{u}$

$f(x)$ is the objective function describing the mathematical formula of the aim. $u$ and $I$ are upper and lower bounds of the variable $x$, respectively.

\section{Sequential quadratic programming}

The SQP algorithm is a generalization of Newton's method for an unconstrained optimization. At any iteration k, the SQP employs quadratic approximation to characterize the objective function in the following expressions (Nash and Sofer 1996; MathsWork, 2001):

Minimize $\left[\nabla f\left(x_{k}\right)\right]^{\top} d_{k}+d_{k}^{T} \nabla^{2} L\left(x_{k}, \lambda_{k}\right) d_{k}$

Subjects to:

$c_{i}\left(x_{k}\right)+\left[\nabla c_{i}\left(x_{k}\right)\right]^{\top} d_{k}=0 ; i=1,2, \ldots, M_{E}$

$c_{i}\left(x_{k}\right)+\left[\nabla c_{i}\left(x_{k}\right)\right]^{\top} d_{k} \leq 0 ; i=M_{E}+1, \ldots, M$

where $L(x, \lambda)=f(x)+\sum_{i=1}^{M} \lambda_{i} c_{i}(x)$.

As can be seen from the aforementioned expressions, the Hessian matrix needs to be updated at every iteration. In addition, this matrix must be a positive definite matrix to ensure its convergence. Thus, the Broyden-Fletcher-Goldfarb-Shanno (BFGS) approximation $B_{k}$ is used to replace the Hessian matrix at each iteration and can be updated by using the following formula (Nash and Sofer, 1996):

$$
\begin{aligned}
& \mathrm{B}_{\mathrm{k}+1}=\mathrm{B}_{\mathrm{k}}-\frac{\mathrm{B}_{\mathrm{k}} \mathrm{s}_{\mathrm{k}} \mathrm{s}_{\mathrm{k}}^{\mathrm{T}} \mathrm{B}_{\mathrm{k}}}{\mathrm{s}_{\mathrm{k}}^{\mathrm{T}} \mathrm{B}_{\mathrm{k}} \mathrm{s}_{\mathrm{k}}}+\frac{\mathrm{y}_{\mathrm{k}} \mathrm{y}_{\mathrm{k}}^{\mathrm{T}}}{\mathrm{y}_{\mathrm{k}}^{\mathrm{T}} \mathrm{s}_{\mathrm{k}}} \\
& \mathrm{s}_{\mathrm{k}}=\mathrm{x}_{\mathrm{k}+1}-\mathrm{x}_{\mathrm{k}} \\
& \mathrm{y}_{\mathrm{k}}=\nabla \mathrm{L}\left(\mathrm{x}_{\mathrm{k}+1}, \lambda_{\mathrm{k}}\right)-\nabla \mathrm{L}\left(\mathrm{x}_{\mathrm{k}}, \lambda_{\mathrm{k}}\right)
\end{aligned}
$$

To find the step $d_{k}$, a line search must be applied. Unlike the unconstrained optimization where the optimal step length can be chosen by minimizing the objective function directly along a given 
search direction, it needs to satisfy all the constraints at the same time. This often causes conflict and usually makes obtained solutions infeasible. So, it is necessary to include these criteria. To avoid this conflict, the merit or penalty function is applied as follows (MathsWork, 2001):

$M(x, v)=f(x)+\sum_{i=1}^{M_{E}} v_{i}\left|c_{i}(x)\right|+\sum_{i=M_{E}+1}^{M} v_{i} \max \left\{c_{i}(x), 0\right\}$

Although, there are some other forms of the merit function such as the augmented Lagrangian merit function, Equation 10 was used MATLAB's optimization toolbox, which is the reference for the SQPbased optimizer used in this paper.

When $x_{k}$ and $d_{k}$ have already been attained somehow from the previous iteration, the $x_{k+1}$ was computed by $x_{k+1}=x_{k}+\alpha_{k} d_{k}$, where the step length $\alpha_{k}$ is to minimize the merit function in the form of $\mathrm{M}\left(\mathrm{x}_{\mathrm{k}}+\alpha_{\mathrm{k}} \mathrm{d}_{\mathrm{k}}, v\right)$. By repeating these processes, solutions found obviously satisfied all constraints while minimizing the objective function. Nevertheless, this generated sequence converges to a local minimum only due to the use of gradient information.

\section{Evolutionary programming}

Evolutionary programming was invented by Fogel et al. (1966). At this time, artificial intelligence was limited to two main avenues of investigation: modeling the human brain or neural networks and modeling the problem solving behavior of human experts or heuristic programming. Both focused on emulating humans as the most advanced intelligent organism produced by evolution. The alternative, envisioned by Fogel, was to refrain from modeling the end product of evolution, but rather to model the process of evolution itself as a vehicle for producing intelligent behavior. Fogel et al. (1966) viewed intelligence as a composite ability to make predictions in an environment coupled with the translation of each prediction into a suitable response in light of a given goal (for example, to maximize a payoff function). Thus, the viewed prediction is a prerequisite for intelligent behavior. The modeling of evolution as an optimization process was a consequence of Fogel's expertise in the emerging fields of biotechnology (at the time defined as the utilization of mathematics to describe the functioning of a human operator), cybernetics and engineering.

This method involves a random search technique. Some researchers (Yuryevich and Wong, 1999; Lai and Ma, 1995, Lai 1998) have applied the EP of various forms to solve the OPF problem. The solution obtained was based on the fitness measure of members of selected population. Hence, the effectiveness of the EP depends on the computation of the fitness function. In this paper, the fitness function is simple and is the direct sum of the objective function and some penalty $\gamma$. This penalty was introduced to handle all constraints and to simply classify members of the population into two categories, namely a feasible set $(\psi)$ and an infeasible set $(\vartheta)$. The fitness function is herein defined by:

$f\left(p_{i}\right)= \begin{cases}F_{T}\left(p_{i}\right) & \text { for } p_{i} \in \psi \\ F_{T}\left(p_{i}\right)+\gamma & \text { for } p_{i} \in \vartheta\end{cases}$

From Equation 14, $\gamma$ denotes a penalty when any considered member does not belong to the feasible region. This penalty is positive and is added up to increase the fitness function. It is likely that an increased fitness value is highly possible to be discarded due to competition and selection. The value of $\gamma$ to ensure that an infeasible member of the population must be eliminated is given as:

$\gamma \geq \max _{\mathrm{p}_{\mathrm{i}}}\left\{\mathrm{F}_{\mathrm{T}}\left(\mathrm{p}_{\mathrm{i}}\right)\right\}$

The EP technique consists of the following steps:

1. An initial sampling of the population $p_{i} \in \psi$, is made on the basis of uniform random selection with $N_{p}$ members, where $p_{i}=\left[p_{i 1} p_{i 2} \ldots\right.$ $p_{\text {in] }}$.

2. Each offspring $q_{i}$ is then generated through the mutation operator applied to each member $p_{i}$ in which $q_{i j}=p_{i j}+N\left(0, \sigma^{2}\right)$, where $p_{i j}$ is the $j$-th element of $\mathrm{p}_{\mathrm{i}}$. The variance $\sigma^{2}$ is given by the following expression:

$$
\sigma_{j}=\beta_{j} \frac{f_{p i}}{f_{a v e}}\left(p_{j, \max }-p_{j, \text { min }}\right),
$$

Where $\beta_{\mathrm{j}}$ is suggested to be in between 0 and 1 and $f_{\text {ave }}$ is the average fitness value of the population (Yang et al., 1996; Lai and Ma, 1995; Yuryevich and Wong, 1999).

3. A competing pool for competition and selection of offspring and initial members are formed and their fitness functions are evaluated. Each member of the pool must compete with other members to get its chance for surviving. The selection is based on evaluation of a weighting value $W_{p}$ of each member, randomly. The weighting value is given by:

$$
\begin{aligned}
& \mathrm{W}_{\mathrm{p}}=\sum_{\mathrm{h}=1}^{\mathrm{Q}} \mathrm{W}_{\mathrm{h}} \\
& \mathrm{W}_{\mathrm{h}}=\left\{\begin{array}{lr}
1 & \mathrm{f}\left(\mathrm{p}_{\mathrm{i}}\right)>\mathrm{f}\left(\mathrm{p}_{\mathrm{r}}\right) \\
0 & \text { otherwise }
\end{array}\right.
\end{aligned}
$$

where $Q$ is some largely positive number and $p_{r}$ is a uniformly random-selected member.

4. Half of the population from the competing pool that depend on their weighting values will survive to the next generation for creating their offspring.

5. This iterative process will be stopped when the termination criteria, for example reaching the maximum number of generation are satisfied.

This can be summarized briefly as shown in the flowchart of Figure 1 .

\section{ADAPTIVE TABU SEARCH}

The tabu search method (Glover and Laguna, 1997) is an iterative process that searches for the best solution by moving from a current solution to find a better solution repeatedly. One of the important features of the TS method is its tabu list that keeps the history of search paths. The information in the list is used for finding a new direction of search movement. Every 'new' is expected to search for a better solution and ultimately the optimum one. Another feature of the tabu search method is its aspiration criterion. The aspiration criterion provides preferable characteristics of any possible solutions. It is particularly useful for the selection of a 


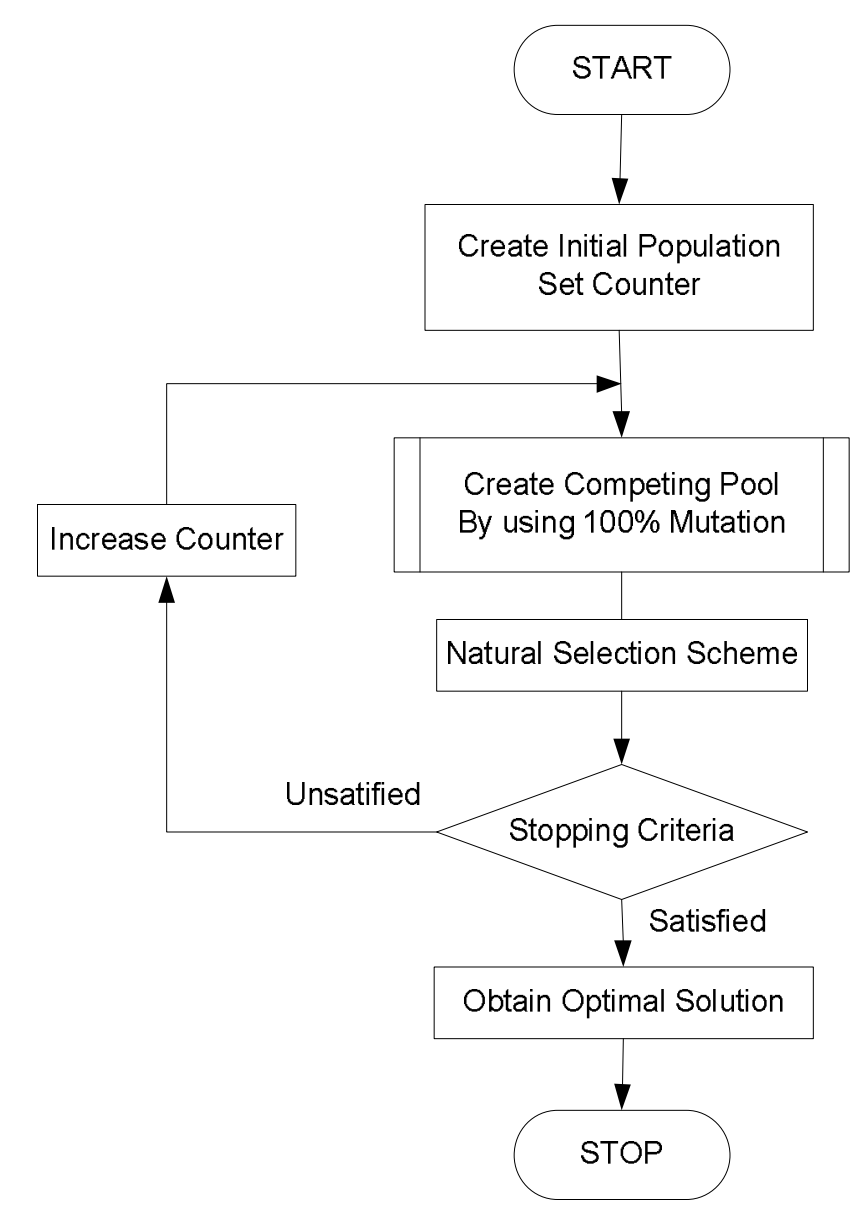

Figure 1. Flowchart of the EP procedure.

proper solution from a set of satisfied solutions.

In order to improve the performance of the tabu search method, we have proposed two additional mechanisms namely backtracking and adaptive search radius. The enhanced version of the tabu search method has been named the adaptive tabu search (Kulworawanichpong et al., 2004; Pungdownreung et al., 2007). Regarding to the intensification mechanism, the back-tracking mechanism allows the search to look backward to some previous solutions stored in the tabu list. This mechanism may become necessary when the search encounters an entrapment caused by a local solution. An alternative solution is then chosen from the current and the previous solutions. With the back-tracked solution, a new search space is created. Given this new search space to explore, the search moves in a new direction away from that approaching the local solution. Note that the new solution chosen here is not necessary to be the best solution within the current search space but it helps the search to escape from an entrapment.

As shown in Figure 2, from the starting point $x_{1}$, a neighborhood $N\left(x_{1}\right)$ given as a set of point around $x_{1}$ with a certain radius $r$ is randomly generated. The best solution $x_{2}$ among them is selected randomly for creating the next neighborhood $\mathrm{N}\left(\mathrm{x}_{2}\right)$ and is also put into the $T L$ if it is not there before. However, the forbidden that moves in the TL can be released if some conditions are satisfied according to aspiration criteria. This method can be performed step-

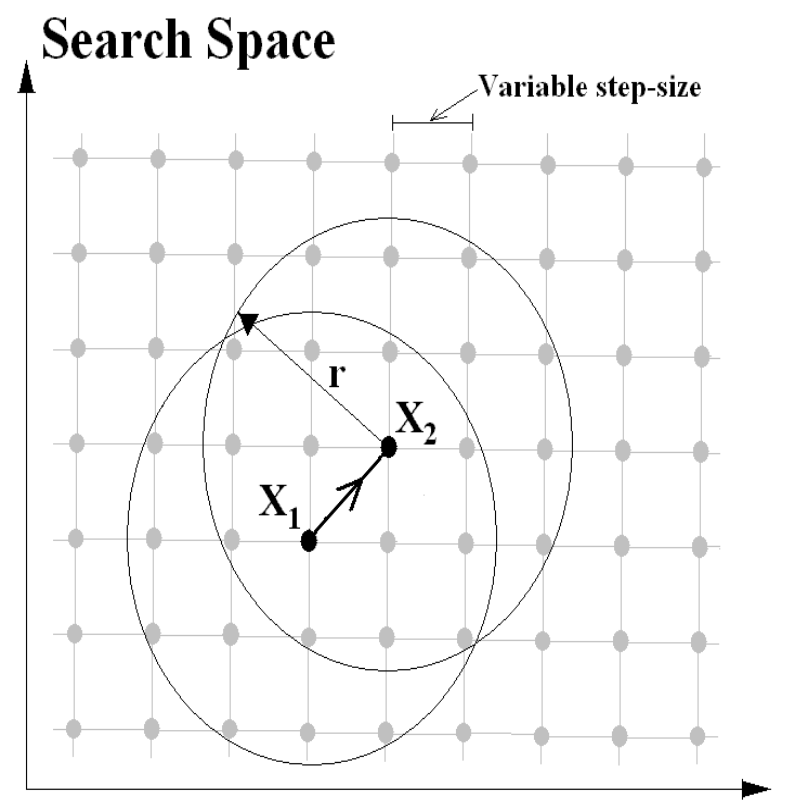

Figure 2. Search space and neighborhood of ATS.

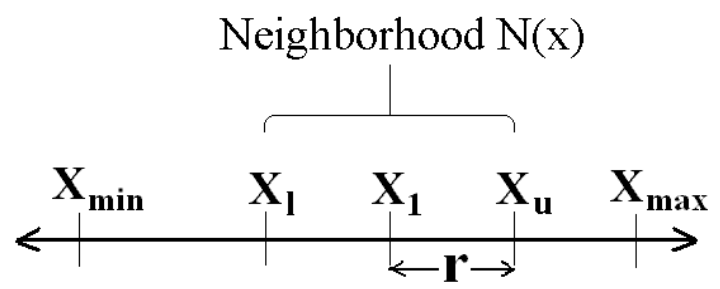

Figure 3. Radius of a neighborhood.

by-step as follows:

1. Generate randomly an initial solution $x_{0}$ from the feasible set. Set $x_{0}$ is an initial optimal solution.

2. Create randomly a neighborhood of a current optimum. As briefly described in the abstract, the TS was developed based on a discrete-variable problem. Applying the TS to a continuous-variable search space needs some modification. With a radius $r$ given by the Equation 4 and shown in Figure 3, each member of the neighborhood is defined by $x_{2}=x_{1}+\alpha r\left(x_{\max }-x_{\min }\right)$, where $\alpha$ is a random number generated in the range of $[-1,1], x_{1}$ is a previously visited solution and $x_{2}$ is a randomly generated member of neighborhood.

$r=\frac{x_{u}-x_{1}}{x_{\text {max }}-x_{\text {min }}}$

3. Let $x_{b}$ be the best solution in the neighborhood. Update the TL if 


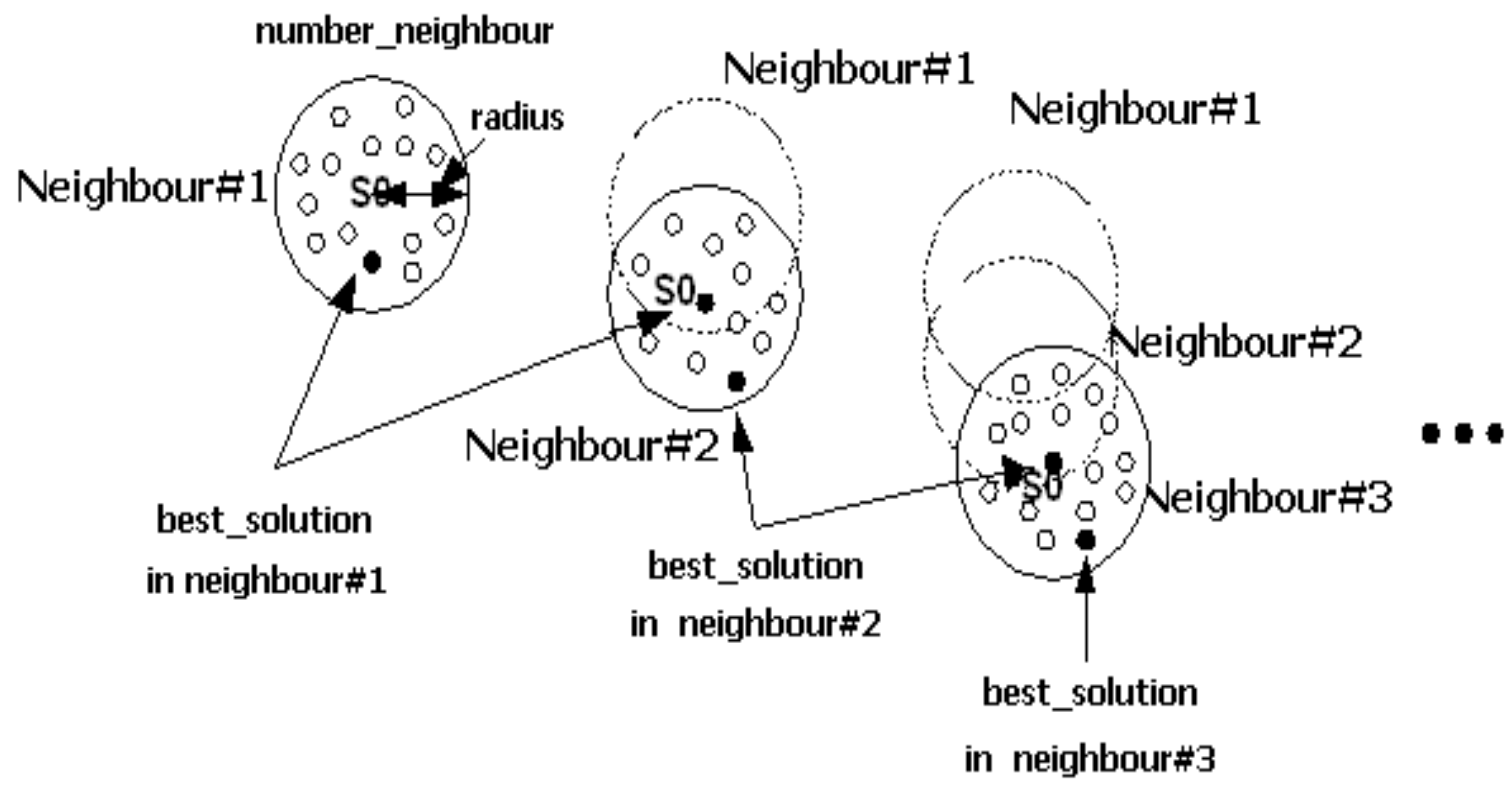

Figure 4. Movement of ATS solutions.

$\mathrm{x}_{\mathrm{b}}$ is not in the list.

4. Check the termination criteria, such as the maximum number of iteration and the aspiration criteria.

Many forms of aspiration criteria are used in different problems to allow us to override the TL and change the direction of movement if all the solutions found along the current direction cannot be better within a certain number of consecutive iteration. The demonstration of TS movements is as shown in Figure 4. This can be summarized briefly as shown in the flowchart of Figure 5.

\section{OPTIMAL POWER FLOW SOLUTION USING ADAPTIVE TABU SEARCH}

To apply the ATS algorithm to an OPF problem, all relevant variables must be re-defined in discrete form with a very small variable step-size. It notes that, throughout the paper, variable stepsizes of power output, voltage-magnitude at controlled buses and ULTC tap are all set to be $1 \times 10^{-4} \mathrm{p}$.u. for all test cases.

As all neighborhood of a current solution are not explored, a certain number of the neighborhood members are chosen to form candidate to the next move. So, $\mathrm{N}_{\mathrm{NH}}$ is set as 10 in this paper. Also, the radius of neighborhood is selected at $r=0.10$. To precede the TS method, TL and AC must be specified. These two parameters critically depend on the nature of problems and they could be varied when a different system is applied. In this paper, TL is capable to store previously visited solutions up to 10 places, 5 to 30 is suggested by Lin et al. (2002). When the searching process is trapped at a local minimum, the AC is activated to release forbidden moves to gain better solutions. In this paper, after 10 moves, if the best solution obtained thus far cannot be improved, then it releases the forbidden move.

The OPF based on the ATS method consists of the following procedures.

\section{START:}

- Set the counter $k=0$

- Randomly generate an initial feasible solution

$\tilde{\mathrm{u}}_{\mathrm{k}}=\left[\begin{array}{llll}\mathrm{P}_{\mathrm{Gi}, \mathrm{k}}^{(*)} & \mathrm{V}_{\mathrm{j}, \mathrm{k}}^{(*)} & \mathrm{V}_{\mathrm{ref}}^{(*)} & \mathrm{T}_{\mathrm{p}, \mathrm{k}}^{(*)}\end{array}\right]^{\mathrm{T}}$

LOOP:

1) Randomly generate $\tilde{\mathrm{u}}^{(\mathrm{q})}{ }_{\mathrm{k}} \in \mathrm{N}\left(\tilde{\mathrm{u}}_{\mathrm{k}}\right)$

for $\mathrm{q}=1: \mathrm{N}_{\mathrm{NH}}$

$$
\begin{aligned}
& \mathrm{P}_{\mathrm{Gi}}^{(\mathrm{q})}=\mathrm{P}_{\mathrm{Gi}, \mathrm{k}}^{(*)}+\alpha \cdot \mathrm{r} \cdot\left(\mathrm{P}_{\mathrm{Gi}}^{\max }-\mathrm{P}_{\mathrm{Gi}}^{\min }\right), \mathrm{i}=1,2, \ldots, \mathrm{N}_{\mathrm{G}}-1 \\
& \mathrm{~V}_{\mathrm{j}}^{(\mathrm{q})}=\mathrm{V}_{\mathrm{j}, \mathrm{k}}^{(*)}+\alpha \cdot r \cdot\left(\mathrm{V}_{\mathrm{j}}^{\max }-\mathrm{V}_{\mathrm{j}}^{\min }\right), \mathrm{i}=1,2, \ldots, \mathrm{N}_{\mathrm{PV}} \\
& \mathrm{V}_{\mathrm{ref}}^{(\mathrm{q})}=\mathrm{V}_{\mathrm{ref}, \mathrm{k}}^{(*)}+\alpha \cdot r \cdot\left(\mathrm{V}_{\mathrm{ref}}^{\max }-\mathrm{V}_{\mathrm{ref}}^{\min }\right) \\
& \mathrm{T}_{\mathrm{p}}^{(\mathrm{q})}=\mathrm{T}_{\mathrm{p}, \mathrm{k}}^{(*)}+\alpha \cdot \mathrm{r} \cdot\left(\mathrm{T}_{\mathrm{p}}^{\max }-\mathrm{T}_{\mathrm{p}}^{\min }\right), \mathrm{i}=1,2, \ldots, \mathrm{N}_{\mathrm{T}}
\end{aligned}
$$

2) Evaluate feasibility and the objective function of candidates for $q=1: N_{N H}$

- Solving power flow equations

- Checking feasibility

Evaluate the objective function if it is feasible

3) Obtain the best solution from the candidates

- Check for the forbidden move

- Check AC satisfaction

- Accept the solution and update TL if satisfied

4) Check the termination criteria

- If satisfied, Update the counter and go to LOOP

- Otherwise, Go to STOP

STOP:

- The optimal solution is already obtained

- The searching process is terminated. 


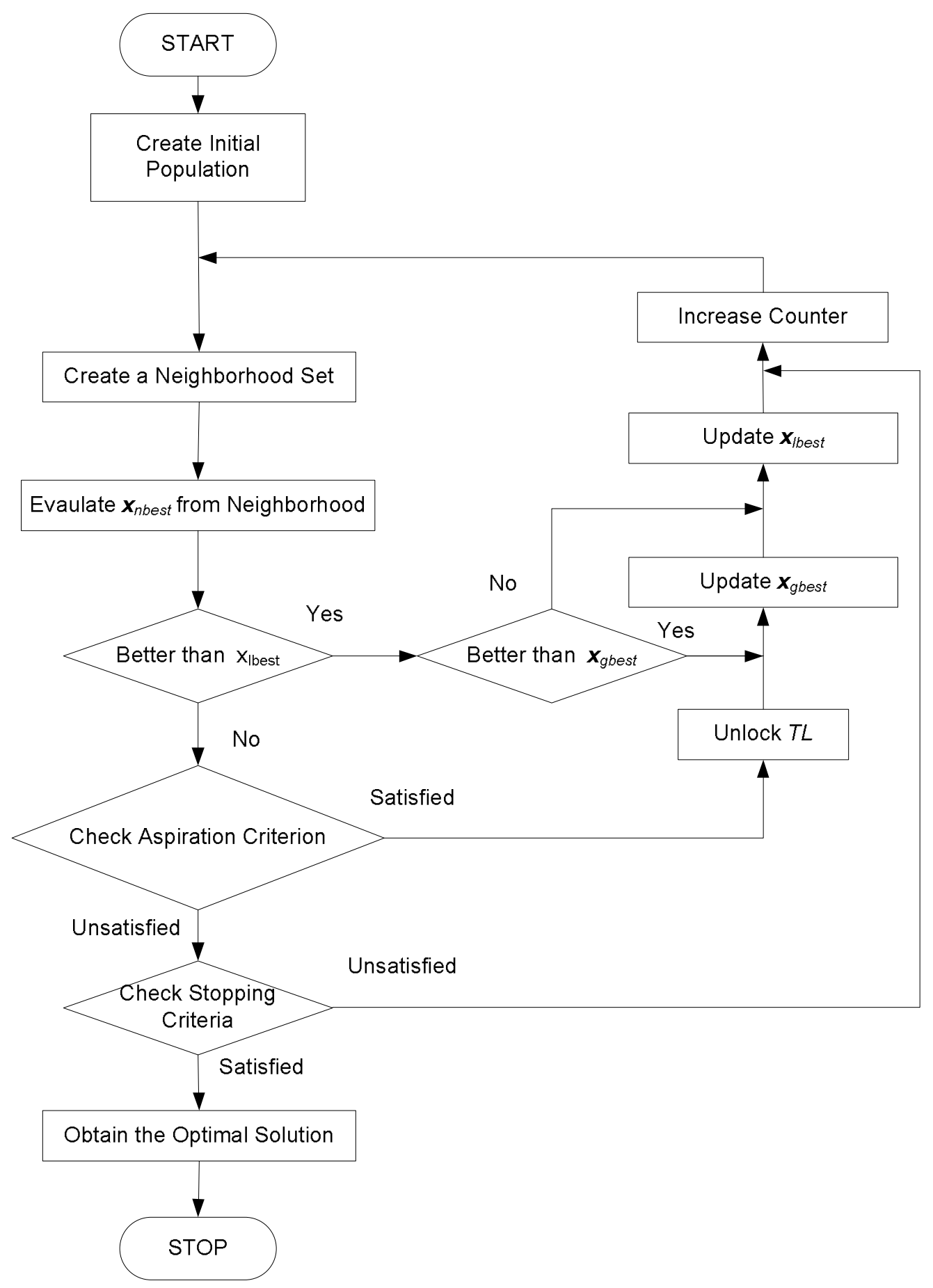

Figure 5. Flowchart of the ATS procedure.

\section{SIMULATION RESULTS}

Although, modern electric power system consists of many types of power plants, in this research, the tests focused on fossil power generation units only. A simple model of such a generator is made from its input fuel cost in $\Re / h$ and corresponding power output was generated in $\mathrm{MW}$ as input and output variables, respectively 


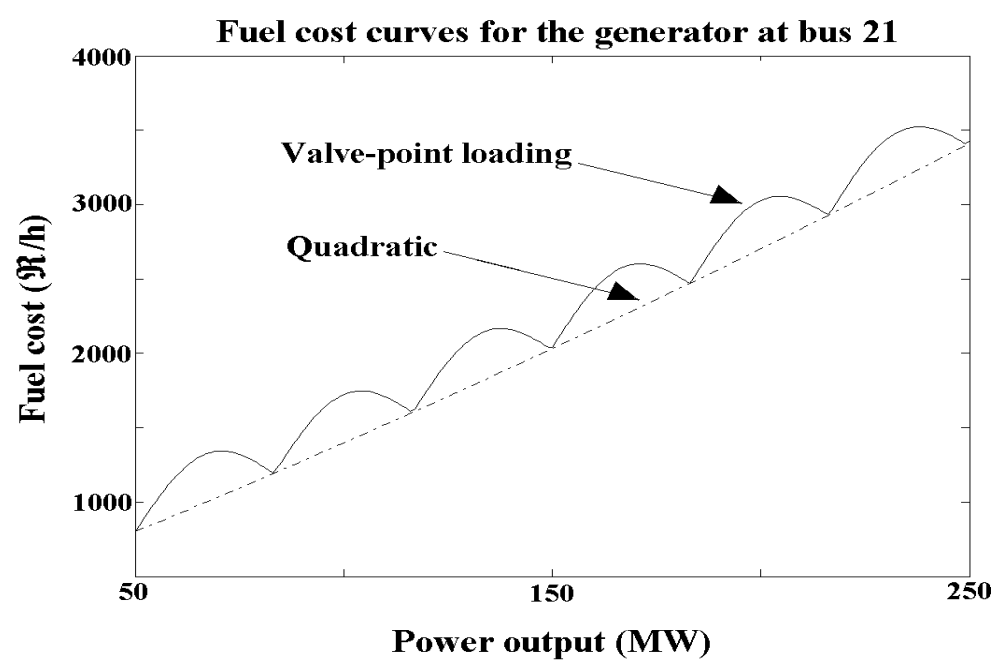

Figure 6. Fuel cost curve of a selected generator.

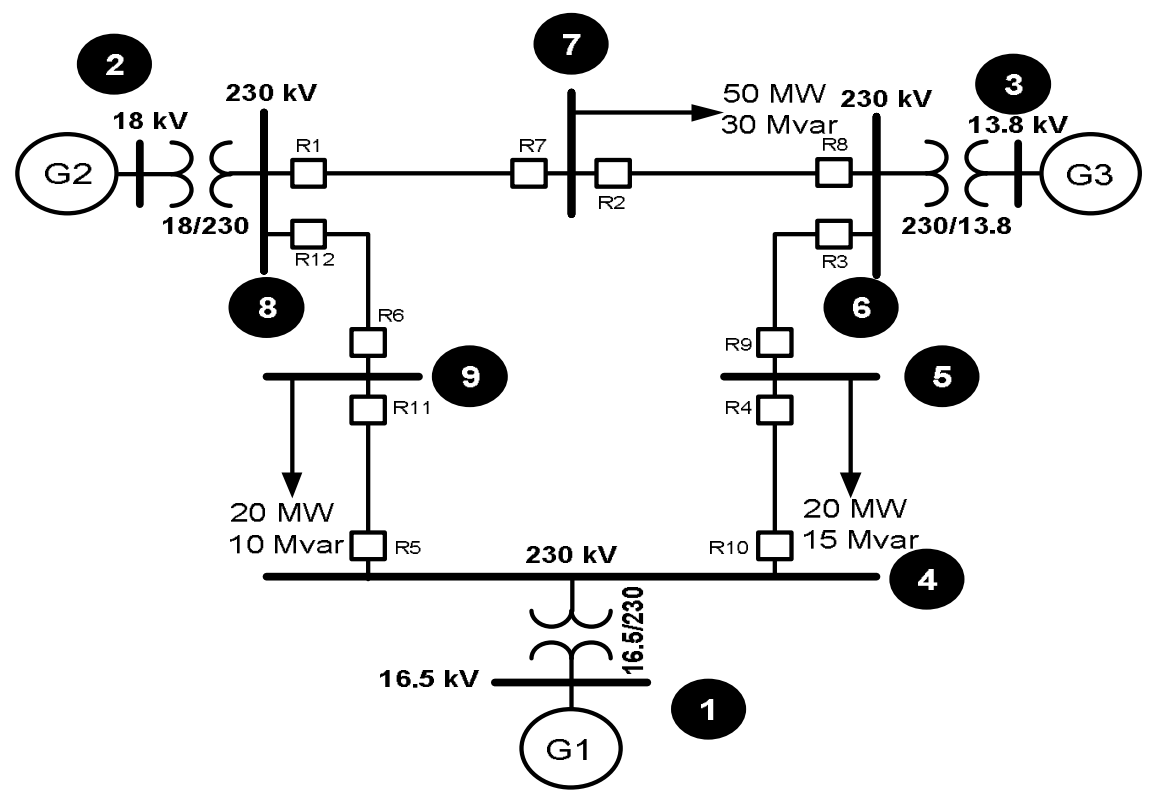

Figure 7. IEEE 9-bus test power system.

(Kulworawanichpong and Sujitjorn, 2002). The test case scenarios were divided into three main conditions. There were smooth and non-smooth fuel-cost curve conditions. In the smooth curve case, all generators' fuel-cost curves were quadratic whilst the second test employed a valvepoint loading function as shown in Figure 6 (Walters and Sheble, 1993; Yang et al., 1996). The last test case was to employ the system voltage profile as the system objective to be minimized. Fuel cost function of each generator connected to the system is generally given in the form of valve-point loading function with having a quadratic term in it and is expressed by:

$f\left(P_{G i}\right)=A_{i}+B_{i} P_{G i}+C_{i} P_{G i}^{2}+\left|E_{i} \sin F_{i}\left(P_{G i}^{m i n}-P_{G i}\right)\right| \Re / h$

In this paper, 9-bus and 300-bus test systems as shown in Figures 7 and 8 were used to perform the effectiveness 

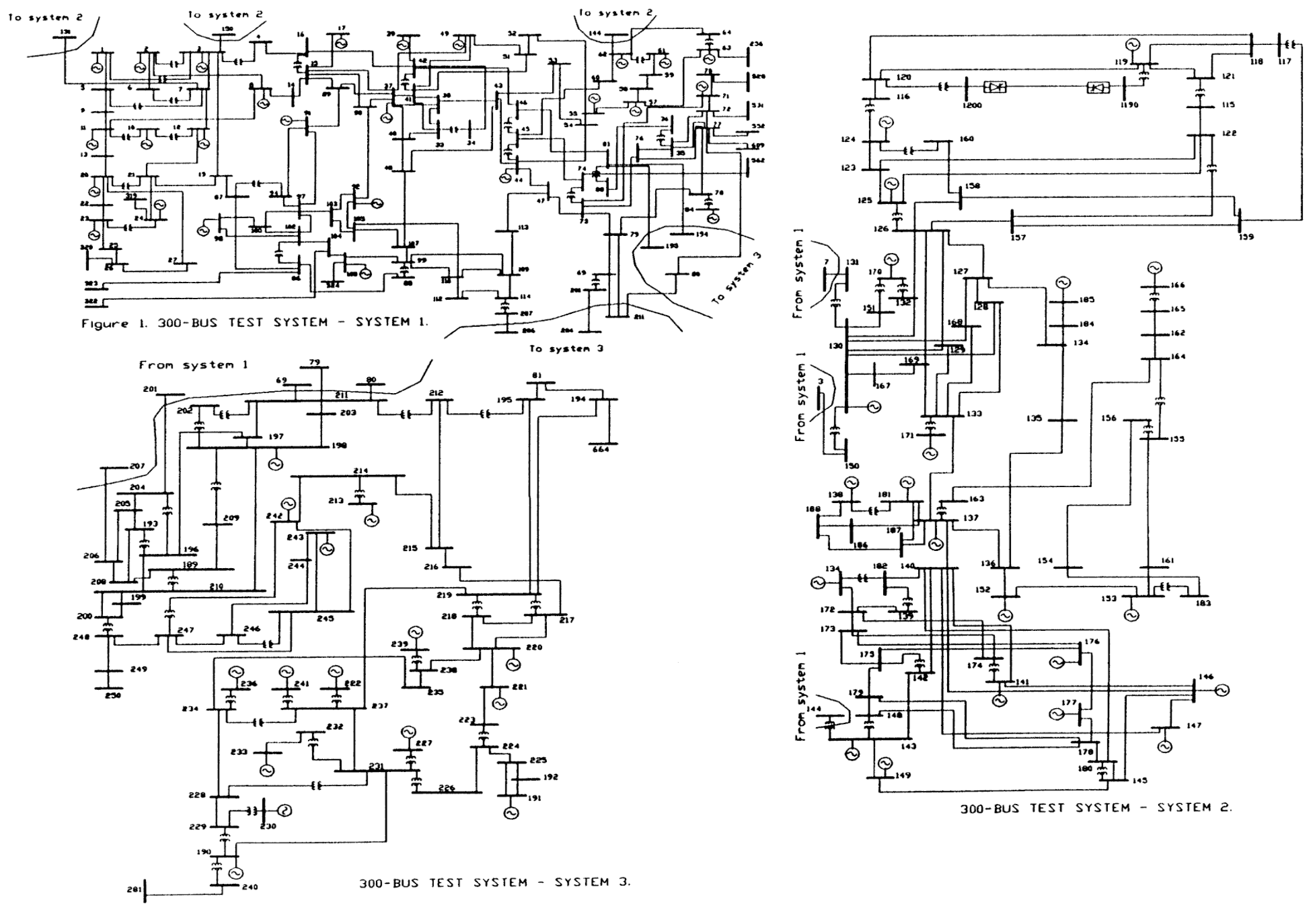

Figure 8. IEEE 300-bus test power system (Sanchez, 2009). 
Table 1. Simulation results of the 9-bus test system with quadratic fuel-cost function.

\begin{tabular}{lccccccccc}
\hline \multirow{2}{*}{ Statistic } & \multicolumn{3}{c}{ Cost function $(\Re)$} & \multicolumn{3}{c}{ SSVD } & \multicolumn{3}{c}{ Execution time $(\mathbf{s})$} \\
\cline { 2 - 9 } & SQP & EP & ATS & SQP & EP & ATS & SQP & EP & ATS \\
\hline Minimum & 4205.9 & 4205.9 & 4205.6 & 0.0499 & 0.0492 & 0.0477 & 1.4 & 68.3 & 12.6 \\
Mean & 4205.9 & 4205.9 & 4206.0 & 0.0499 & 0.0497 & 0.0489 & 2.0 & 110.1 & 22.5 \\
Maximum & 4205.9 & 4206.0 & 4206.1 & 0.0499 & 0.0498 & 0.0496 & 5.2 & 174.0 & 37.0 \\
SD & 0.00 & 0.01 & 0.07 & 0.0000 & 0.0001 & 0.0005 & 0.6 & 25.2 & 5.5 \\
\hline
\end{tabular}

SQP: sequential quadratic programming; EP: evolutionary programming; ATS: adaptive tabu search; SSVD: sum of square of system voltage deviation.

Table 2. Simulation results of the 300-bus test system with quadratic fuel-cost function.

\begin{tabular}{|c|c|c|c|c|c|c|c|c|c|}
\hline \multirow{2}{*}{ Statistic } & \multicolumn{3}{|c|}{ Cost function (R) } & \multicolumn{3}{|c|}{ SSVD } & \multicolumn{3}{|c|}{ Execution time (s) } \\
\hline & SQP & EP & ATS & SQP & EP & ATS & SQP & EP & ATS \\
\hline Minimum & 173426.8 & 173899.2 & 174296.1 & 0.0915 & 0.1598 & 0.1684 & 4887.6 & 3175.3 & 689.7 \\
\hline Mean & 177337.5 & 174396.0 & 174693.1 & 0.2015 & 0.2554 & 0.3175 & 5035.7 & 3787.0 & 754.3 \\
\hline Maximum & 182345.0 & 174689.1 & 175498.4 & 0.3128 & 0.5212 & 0.5125 & 6536.5 & 5273.4 & 868.5 \\
\hline SD & 3381.3 & 168.7 & 282.7 & 0.0664 & 0.0595 & 0.0924 & 347.5 & 452.1 & 49.5 \\
\hline
\end{tabular}

SQP: sequential quadratic programming; EP: evolutionary programming; ATS: adaptive tabu search; SSVD: sum of square of system voltage deviation.

of the proposed methods. The SQP used in these tests is of MATLAB optimization toolbox. Limits of voltage magnitudes for voltage-controlled buses and limits of tap setting for ULTCs used for all test cases were 0.95 to 1.05 p.u. and 0.90 to 1.10 p.u., respectively.

More careful assessments are needed to confirm the performance of the proposed method. In this paper, the IEEE 9-bus and IEEE 300-bus test systems with 5 and 244 control variables, respectively, were used for the test with two fuel-cost functions and one voltage deviation minimization. For voltage profile calculation, the sum of the square of system voltage deviation (SSVD) was expressed as follows:

$$
\operatorname{SSVD}=\sum_{\substack{\mathrm{i}=1 \\ \mathrm{i} \neq \mathrm{CB}}}^{\mathrm{N}_{\mathrm{B}}}\left|\mathrm{V}_{\text {rated }}-\mathrm{V}_{\mathrm{i}}\right|^{2}
$$

where $V_{\text {rated }}=1.00$ p.u. and $C B$ denotes controlled buses

\section{Smooth fuel-cost function (Quadratic case)}

In this circumstance, a quadratic fuel-cost function was assigned to all generators. The test was performed on an Intel $^{\theta} 1.7 \mathrm{GHz}, 1.0 \mathrm{~GB}$ RAM with MATLAB. It was noted that all optimization methods used in this test was performed with 40 computational trials per method. The SQP used in these tests is of MATLAB optimization toolbox. The parameter setting for the SQP was fixed as follows:

1. Tolerance for control variables $=1 \times 10^{-4}$

2. Tolerance for objective function $=1 \times 10^{-8}$

3. Termination criterion for constraint violation $=1 \times 10^{-6}$

4. Maximum number of function evaluation $=(100 \times$ total number of control variables).

Referring to the EP algorithm (Yang et al., 1996; Lai and Ma, 1995; Yuryevich and Wong, 1999), EP parameters used in this paper are given as:

1. Total number of population $\mathrm{N}_{\mathrm{P}}=30$

2. Mutation scaling factor $\beta=0.03$

3. Maximum number of generation $=1000$

4. Termination criterion for the change of the objective function is set to $1 \times 10^{-8}$.

For the TS, all parameters that give the best results are given as:

1. Total number of neighbourhood, $N_{H}=10$

2. Radius of neighbourhood, $r=0.1$

3. Maximum number of generation $=1000$

4. Termination criterion for the change of the objective function is set to $1 \times 10^{-8}$

As shown in Tables 1 and 2, the SQP can find the lowest 
Table 3. Simulation results of the 9-bus test system with non-smooth fuel-cost function.

\begin{tabular}{lccccccccc}
\hline \multirow{2}{*}{ Statistic } & \multicolumn{3}{c}{ Cost function $(\Re)$} & \multicolumn{3}{c}{ SSVD } & \multicolumn{3}{c}{ Execution time (s) } \\
\cline { 2 - 9 } & SQP & EP & ATS & SQP & EP & ATS & SQP & EP & ATS \\
\hline Minimum & 4559.4 & 4592.8 & 4589.9 & 0.0239 & 0.0011 & 0.0009 & 1.4 & 47.6 & 8.0 \\
Mean & 4758.6 & 4662.5 & 4682.1 & 0.0452 & 0.0121 & 0.0094 & 7.6 & 90.6 & 13.2 \\
Maximum & 5257.7 & 4799.1 & 4820.7 & 0.0502 & 0.0364 & 0.0218 & 18.0 & 224.6 & 24.7 \\
SD & 158.5 & 49.9 & 61.5 & 0.0067 & 0.0086 & 0.0056 & 4.1 & 33.6 & 3.8 \\
\hline
\end{tabular}

SQP: sequential quadratic programming; EP: evolutionary programming; ATS: adaptive tabu search; SSVD: sum of square of system voltage deviation.

Table 4. Simulation results of the 300-bus test system with non-smooth fuel-cost function.

\begin{tabular}{|c|c|c|c|c|c|c|c|c|c|}
\hline \multirow{2}{*}{ Statistic } & \multicolumn{3}{|c|}{ Cost function $(\Re)$} & \multicolumn{3}{|c|}{ SSVD } & \multicolumn{3}{|c|}{ Execution time (s) } \\
\hline & SQP & EP & ATS & SQP & EP & ATS & SQP & EP & ATS \\
\hline Minimum & 211062.7 & 233487.2 & 240813.9 & 0.1211 & 0.3826 & 0.3301 & 4800.5 & 1328.4 & 164.02 \\
\hline Mean & 288970.8 & 256222.5 & 259738.9 & 0.3916 & 0.5209 & 0.4858 & 5085.9 & 2406.6 & 477.69 \\
\hline Maximum & 310574.6 & 282472.6 & 269542.3 & 1.1909 & 0.7558 & 0.7932 & 7221.9 & 5165.9 & 831.22 \\
\hline SD & 25129.8 & 14275.3 & 7287.0 & 0.3025 & 0.0905 & 0.1246 & 469.2 & 1054.0 & 220.15 \\
\hline
\end{tabular}

SQP: sequential quadratic programming; EP: evolutionary programming; ATS: adaptive tabu search; SSVD: sum of square of system voltage deviation.

averaged minimum cost function among them, that is $4205.9 \Re$ with zero SD to indicate its accuracy. Although, the EP can reach the same amount of averaged minimum cost function, it spent very long computation time $(110.1 \mathrm{~s}$ for the EP method and $2.0 \mathrm{~s}$ for the SQP method). Undoubtedly, the SQP is the best choice of a small 9-bus test system with quadratic fuel-cost function in the execution time and minimum cost considerations. In this case, the voltage profiles of the three methods are not significantly different. Table 2 represents simulation results of the 300-bus system. The solution obtained by EP method is the best among the three methods (177.34 $\times 10^{3}, 174.40 \times 10^{3}$ and $174.69 \times 10^{3} \Re$ for SQP, EP and ATS, respectively), but it spent a long execution time (5035.7, 3787.0 and $754.3 \mathrm{~s}$ for SQP, EP and ATS, respectively). So that, the ATS is comparatively better with slightly higher minimum cost function found than those found by the EP but remarkably about 5 -time faster calculation time. However, the SSVD of the solution obtained by the ATS method is relatively high.

\section{Non-smooth fuel-cost function (Valve-point loading case)}

This test case used non-smooth fuel-cost curves (Figure 6 ) to produce system complexity. In this circumstance, there exist many local minima that can effectively trap an inefficient search method. All proposed methods still hold their parameter settings with 40 computational trials as previously described. To asset the effectiveness among them, their simulation results are compared in both accuracy and calculation speed as illustrated in Tables 3 and 4 , respectively.

The results show that, for the 9-bus system, the EP can again obtain the lowest minimum cost function (4758.6, 4662.5 and $4682.1 \Re$ for SQP, EP and ATS, respectively). It also reveals that the solution found by the SQP method is far from a true global minimum. Therefore, it is not appropriate to apply this technique to such a test case. In this test case, the ATS still performed a solution finding with outstanding execution time with satisfactorily accurate results. For the 300-bus system, when comparing the averaged minimum costs obtained among the methods, the EP is the best method (288.97 $\times$ $10^{3} \Re$ for the SQP, $256.22 \times 10^{3} \mathfrak{R}$ for the EP and 259.74 $\times 10^{3} \Re$ for the ATS). However, with calculation time comparison, the ATS method can obtain the solution with the fastest calculation time consumed (477.69 s), while the others are very far behind (5085.9 and $2406.6 \mathrm{~s}$ for the SQP and EP, respectively).

\section{Sum of square of voltage deviations and power losses}

The characterization of system voltage profiles for the test systems was given by the sum of square of voltage 
Table 5. Simulation results of the 9-bus test system for SSVD minimization.

\begin{tabular}{lccc}
\hline Statistic & SSVD (p.u.) & Cost function $(\Re)^{\star}$ & ${\text { Cost function }(\Re)^{+}}^{{ }^{\star}}$ \\
\hline Minimum & 0.00056334 & 4265.2 & 4935.7 \\
Mean & 0.00056615 & 4295.2 & 5388.6 \\
Maximum & 0.00057324 & 4325.9 & 5947.0 \\
SD & 0.00000252 & 15.3 & 271.3 \\
\hline
\end{tabular}

${ }^{+}$Valve-point loading fuel-cost function; *Quadratic fuel-cost function. SSVD: sum of square of system voltage deviation.

Table 6. Simulation results of the 300-bus test system for SSVD minimization.

\begin{tabular}{|c|c|c|c|}
\hline Statistic & SSVD (p.u.) & Cost function $(\Re)^{*}$ & Cost function $(\Re)^{+}$ \\
\hline Minimum & 0.0075 & 193205.2 & 292145.5 \\
\hline Mean & 0.0119 & 203574.9 & 318387.5 \\
\hline Maximum & 0.0182 & 218945.4 & 348515.6 \\
\hline SD & 0.0026 & 5845.0 & 14333.3 \\
\hline
\end{tabular}

${ }^{*}$ Quadratic fuel-cost function; ${ }^{+}$Valve-point loading fuel-cost function. SSVD: Sum of square of system voltage deviation.

Table 7. Comparison of power losses, fuel cost and SSVD minimization for the 9-bus test system with quadratic fuel-cost function.

\begin{tabular}{lccc}
\hline \multirow{2}{*}{ System profile } & \multicolumn{3}{c}{ Objective function } \\
\cline { 2 - 4 } & Power loss & Fuel-cost & SSVD \\
\hline Power losses (MW) & 2.32 & 2.73 & 3.12 \\
Cost function $(\Re)$ & 4232.4 & 4206.0 & 4297.5 \\
SSVD (p.u.) & 0.0496 & 0.0491 & 0.0006 \\
\hline
\end{tabular}

SSVD: Sum of square of system voltage deviation.

deviations as previously described in Equation 20. Here, all control variables were adjusted to gain a minimum voltage deviation for the whole system as good as possible. The aim of this test is to verify that the solutions obtained according to the given objectives in the first two test cases can give a satisfactory system voltage profiles or not. To precede the test, the fuel-cost function was replaced by the SSVD as the new objective function. It notes that this test case was carried out to collect the test results when compare with the solutions obtained by minimizing cost functions. So, only the ATS method was selected to precede the test due to the shortest execution time with the satisfactorily accurate solution. All simulation results of this section are shown on Tables 5 and 6 for the two respective test systems.

As can be seen, it is clear that the minimum cost function and the minimum voltage deviation are mutually exclusive. While minimizing the system voltage deviation, the cost function was significantly raised (4206.0 and $4295.2 \Re$ for fuel-cost and SSVD minimization, respectively, in the case of the 9-bus system with quadratic fuel-cost function). The same trends can be found for the 300-bus test case and the case of valve-point loading fuel-cost function.

In addition, the comparison among power loss, fuelcost and SSVD minimization of the 9-bus test system was investigated and put on Table 7 for more explanations. Table 7 illustrates system performances when minimizing some particular objective. It is obvious that the minimum of the three functions is mutually exclusive. It critically depends on the true main objective of a problem itself. For example, in electrical power generation and transmission viewpoint, the fuel-cost function in general acts as the main criterion to operate the system with system voltage profiles being inequality constraints. 


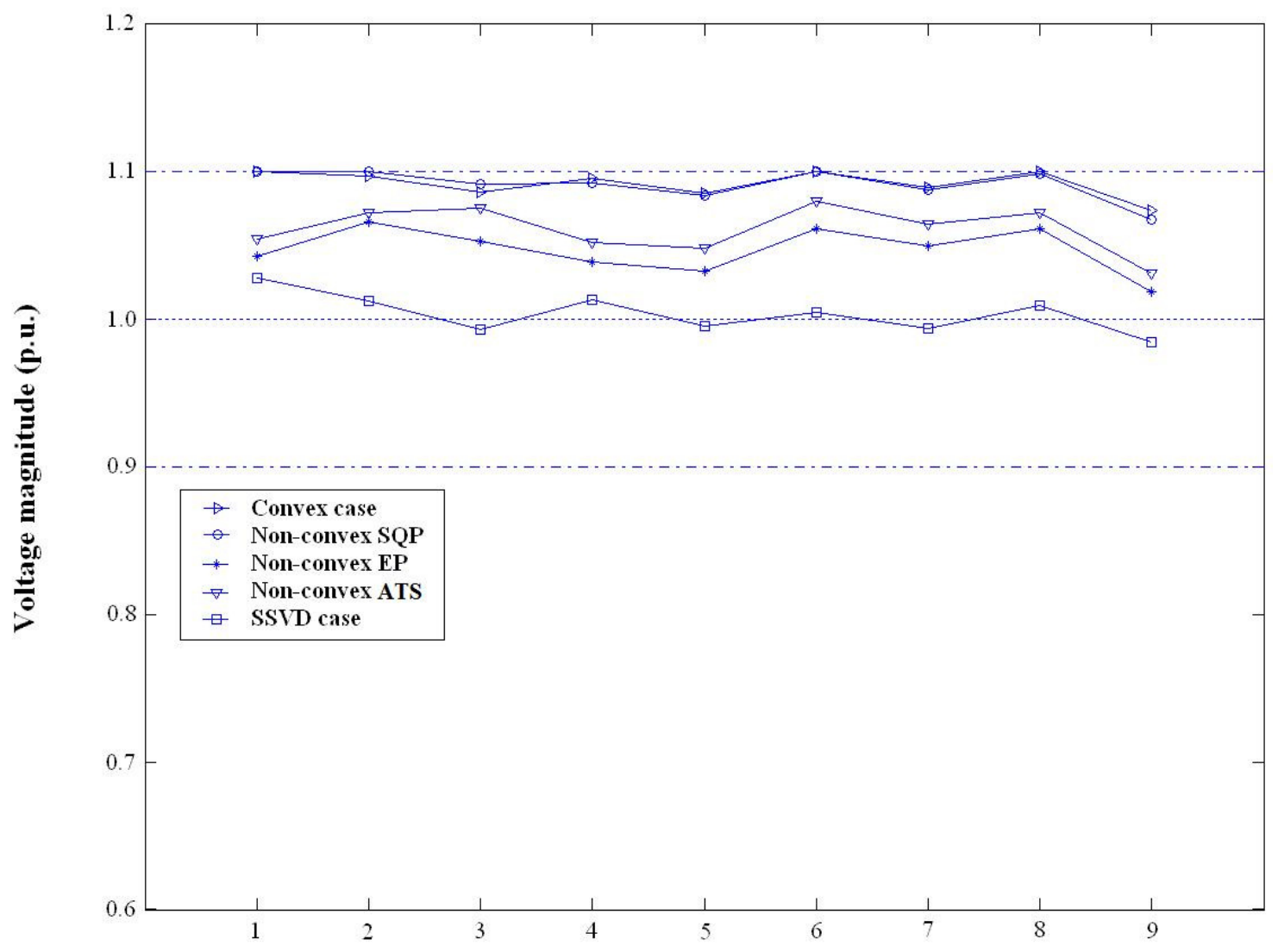

Bus number

Figure 9. System voltage profile of each test case for the 9-bus test system.

In some particular power feeding systems like alternate current (AC) railway power distribution systems (Hill, 1994; Goodman et al., 1998), where electric power is fed at the substation point, there was no generation cost, therefore system voltage deviation becomes obviously critical. Although, the AC railway feeding systems can operate with about $\pm 30 \%$ voltage deviations (White, 1997), it also affects traction drive performances (Hill, 1994b, 1994c), voltage stability and limitation of feeding capacity to railway power systems. Thus, the SSVD minimization is more attractive for this case.

To picture system voltage profiles of the fuel-cost minimization, some test results were selected and presented in Figures 9 and 10, comparatively with the system voltage profile obtained by minimizing SSVD.

\section{DISCUSSION}

For decades, there have been many publications related to solution methods for searching OPF solutions. Many methods either classical or evolutionary optimizations have been continually developed and widely published. This research proposes comparative studies to lead some key conclusions for selecting an appropriate optimization method applied to the OPF problem.

As can be seen, when many local minima exist, typically a non-convex problem, the SQP does not fit to such a circumstance according to their trapped local minimum found. Among the three methods, EP is suitable for a problem that needs very accurate results but does not attend calculation speed. Nonetheless, for a smallscale, convex OPF problem like a small 9-bus power system, the SQP can guarantee that the solution obtained is the global minimum and also provides satisfactory calculation speed, but does not for a largescale system.

In literature (Lai and Ma, 1995; Wong, 1997; Yuryevich and Wong, 1999; Tangpatiphan and Yokoyama, 2008, 2009), the execution time consumed by the SQP is 
Voltage profile in zone 1 (bus 1 - bus 114)

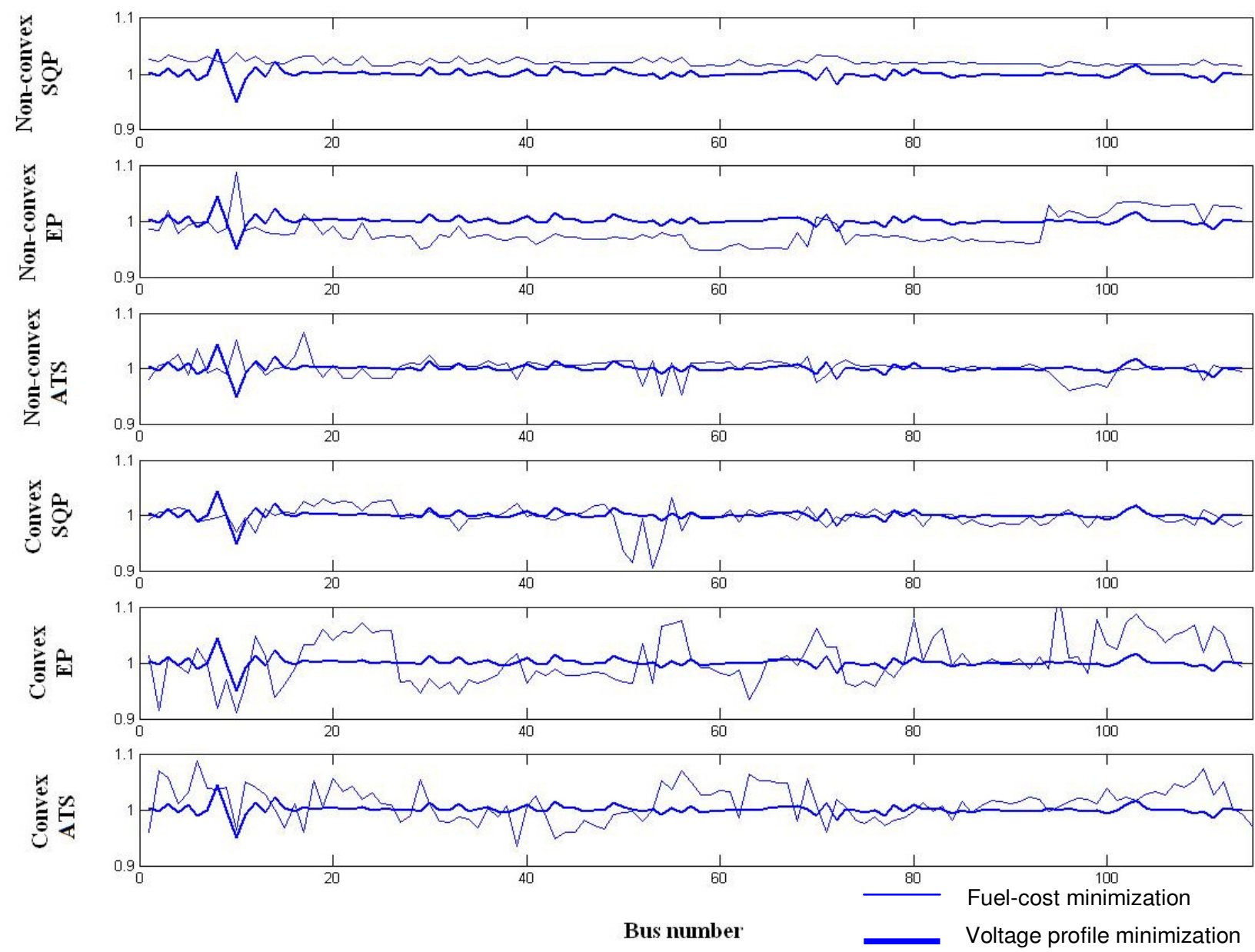

Figure 10. System voltage profile of each test case for the 9-bus test system.

roughly $1 / 6$ of that of the EP. However, this estimated CPU time is evaluated on the IEEE 30-bus test system. For a smaller-sized test system, e.g. 6-bus, 14-bus, etc., the execution time of the SQP can be as fast as $1 / 10$ of that of the EP while a larger-sized test system gives a contrary results. In this work, results from the small 9-bus test system show that the execution times taken by the SQP are $1 / 55$ and $1 / 12$ of those required by the EP for smooth quadratic and non-smooth fuel-cost cases, respectively. In the IEEE 300-bus test system, the SQP consumes longer execution time than that required by the EP, $4 / 3$ and 2 of the execution time consumed by the EP for smooth quadratic and non-smooth fuel-cost cases, respectively. In the same manner, the execution time required by the SQP of the small 9-bus test system is roughly $1 / 11$ and $2 / 3$ of those of the ATS when compared with $1 / 55$ and $1 / 12$ between the SQP and the EP for smooth quadratic and non-smooth fuel-cost cases, respectively. This confirms that the ATS can give satisfacorily execution time for the small 9-bus test system. In the IEEE 300-bus test system, the SQP consumes longer execution time than that required by the ATS, 20/3 and 10 of the execution time consumed by the SQP for smooth quadratic and non-smooth fuel-cost cases, respectively. This confirms the effectiveness of the ATS for solving non-smooth fuel-cost cases of optimal power flow in the large 300-bus test system.

\section{Conclusion}

The ATS is of course like the EP in which to obtain a near global minimum is dependent on their parameter settings and termination criteria. But its calculation time is remarkably less than that spent by the EP or even the SQP for the 300-bus system. In a very complicated OPF 
problem like the second test system with 244 control variables (68 for generation output, 69 for voltage magnitudes and 107 for ULTCs), the ATS can completely escape a deadlock from local minima to reach a near global minimum that other search methods cannot or spend too much calculation time to do so. For applications that need highly accurate solutions, the ATS' parameters can be easily tuned to achieve the requirement at the expense of long calculation time.

\section{ACKNOWLEDGEMENT}

The author would like to thank Professor Sarawut Sujitjorn, School of Electrical Engineering, Suranaree University of Technology, Thailand, for his valuable discussions and help during the period of this research work.

\section{REFERENCES}

Abido MA (2002). Optimal power flow using tabu search algorithm. Electric Power Comp. Syst. 30: 469-483.

Abido MA (2002b). Optimal power flow using particle swarm optimization. Int. J. Elect. Power Ener. Syst., 24(7): 563-571

Denna M, Mauri G, Zanaboni AM (1999) Learning Fuzzy Rules with Tabu Search-An Application to Control. IEEE Trans. Fuzzy Syst., 7: 295-318.

Dommel HW, Tinney WF (1968). Optimal power flow solutions. IEEE Trans. Power Apparat. Syst., 87: 1866-1876.

El-Abiad H, Jaimes FJ (1969). A method for optimum scheduling of power and voltage magnitude.IEEE Trans. Power Apparat. Syst., 88: 413-422.

Fogel LJ, Owens AJ, Walsh MJ (1966). Artificial Intelligence through Simulated Evolution. John Wiley.

Gaing ZL (2005). Constrained optimal power flow by mixed-integer particle swarm optimization. In Proceeding of IEEE Power Engineering Society General Meeting, pp. 243-250.

Glover F, Laguna M (1997). Tabu Search. Kluwer.

Goodman CJ, Siu LK, Ho TK (1998). A review of simulation models for railway systems. In Proceeding of Int. Conf. On Developments in Mass Transit Systems, pp. 80-85.

Herault L (2000). Rescaled simulated annealing-accelerating convergence of simulated annealing by rescaling the states energies. J. Heuristics, 6: 215-252.

Hill RJ (1994a). Electric railway traction - Part 1 electric traction and DC traction motor drives. Power Eng. J., pp. 47-56.

Hill RJ (1994). Electric railway traction - Part 2 traction drives with three-phase induction motors. Power Eng. J., 43-152.

Hill RJ (1994c). Electric railway traction - Part 3 traction power supplies. IEE Power Engineering Journal. 275-286.

Kulowrawanichpong T, Sujitjorn S (2002). Optimal power flow using Tabu search. IEEE Power Eng. Rev., 37-40.

Kulworawanichpong T, Puangdownreung D, Sujitjorn S (2004). Finite convergence of adaptive tabu search. ASEAN J. Sci. Technol. Dev., 21: $103-115$.

Lai LL, Ma JT (1995). Power flow control in FACTS using evolutionary programming. Proceeding IEEE Int. Conf. Evol. Comput., 1: 109-113.

Lai LL (1998) Intelligent system Applications in Power Engineering: Evolutionary Programming and Neural Networks. Johns Wiley \& Sons.

Lin W, Cheng F, Tsay M (2002). An improved tabu search for economic dispatch with multiple minima. IEEE Trans. Power Syst., 17: 108-112.
Mansour MD, Abdel TM (1984). Non-linear VAR optimization using decomposition and coordination. IEEE Trans. Power Apparat. Syst., 103: 246-255.

Mantawy AH, Abdel-Magid YL, Selim SZ (1998). Unit Commitment by Tabu Search. IEE Proc-Gener. Transm. Distrb., 145: 56-64.

MathWorks Inc. (2001). Optimization toolbox user's guide - MABLAB 6.1 Professional, Version 2.1.1, Release 12.1.

Mo N, Zou ZY, Chan KW, Pong TYG (2007). Transient_stability constrained optimal power flow using particle swarm optimisation. IET Gener. Trans. Distrb., 1: 476-483.

Mori H, Hayashi T (1998). New Parallel Tabu Search for Voltage and Reactive Power Control in Power Systems. In Proc. IEEE Int. Symp. Circuits Syst., 3: 431-434.

Mori H, Ogita Y (1999a). Capacitor Placement using Parallel Tabu Search in Distribution Systems. Proc. IEEE Int. Conf. Syst., Man Cybern., 6: 521-525.

Mori H, Sone Y (1999b). Tabu Search Based Meter Placement for Topological Observability in Power System State Estimation. Proc. IEEE Trans. Distrib. Conf., 1: 172-177.

Murlithi MG (1996). Optimal Power Flow for The High Voltage Network of The Kenya Power System. IEEE Afr., 1: 162-168.

Nash SG, Sofer A (1996). Linear and nonlinear programming. McGrawHill.

Oumarou I, Daozhuo J, Cao Y (2009). Particle Swarm Optimization Applied to Optimal Power Flow Solution. Proceeding IEEE Proc-Int. Conf. Natur. Comp., pp. 248-288.

Pradhan B, Lee S (2009). Landslide risk analysis using artificial neural network model focussing on different training sites. Int. J. Phys. Sci., 4: $1-15$.

Puangdownreong D, Kulworawanichpong T, Suwannarongsri S (2007) Application of intelligent search techniques to identify single-phase induction motor's parameters. In Proceeding of the $7^{\text {th }}$ WSEAS International Conference on Simulation Modelling and Optimization,

Sanchez JEC (2009). A complex network approach to analyzing the structure and dynamics of power grids. MSc Thesis. University of Vermont, Burlington, Vermont, USA.

Santos A, Costa GRM (1995). Optimal-Power-Flow Solution by Newton's Method Applied to An Augmented Lagrangian Function. IEE Proc-Gener. Transm. Distrb., 142: 33-36.

Shoults RR, Sun DT (1982). Optimal power flow based upon P-Q decomposition. IEEE Trans. Power Apparat. Syst., 101: 397-405.

Tangpatiphan K, Yokoyama A (2008). Evolutionary Programming Incorporating Neural Network for Transient Stability Constrained Optimal Power Flow. In Proceeding of the IEEE International Conferences Power Syst. Technol., pp. 1-8.

Tangpatiphan K, Yokoyama A (2009). Optimal Power Flow with steadystate voltage stability consideration using Improved Evolutionary Programming. Proceeding IEEE Bucharest Power, pp. 1-7.

Vaisakb K. Srinivas LR (2005). Differential Evolution Approach for Optimal Power Flow Solution. J. Theoretical Appl. Inform. Technol., 261-268.

Walters DC, Sheble GB (1993). Genetic algorithm solution of economic dispatch with valve point loading. IEEE Trans. Power Syst., 8: 13251332.

Wenjuan Z, Fangxing L, Tolbert LM (2008). Voltage Stability Constrained Optimal Power Flow (VSCOPF) with Two Sets of Variables (TSV) for Reactive Power Planning. In Proceeding of the IEEE-PES. Transm. Distrb. Conf. Expo., pp. 1-6.

White RW (1997). AC supply systems and protection. In Proceeding of Forth Vocation School on Electric Traction Systems.

Wood AJ, Wollenburg BF (1996). Power Generation Operation and Control. John Wiley \& Sons.

Wong KP (1997). Computational intelligence applications in unit commitment, economic dispatch and load flow. In Proceeding of the 4th International Conference on Advances in Power System Control, Operation and Management APSCOM-97, pp. 54-59.

Yang H, Yang P, Huang C (1996). Evolutionary programming based economic dispatch for units with non-smooth fuel cost functions. IEEE Trans. Power Syst., 11: 112-118. 
Younes M, Rahli M, Abdelhakem-Koridak L (2007). Optimal Power Flow Based on Hybrid Genetic Algorithm. J. Inform. Sci. Eng., 1801-1816.
Yuryevich J, Wong KP (1999). Evolutionary programming based optimal power flow algorithm. IEEE Trans. Power Syst., 14: 1245-1250. 